\title{
UBIQUITOUS INDOOR GEOLOCATION: A CASE STUDY OF JEWELLERY MANAGEMENT SYSTEM
}

\author{
B. Nikparvar*, A. Sadeghi-Niaraki, P. Azari \\ Dept. of Geodesy and Geomatics, K.N.Toosi Univ. of Tech., Tehran, Iran - bnikparvar@mail.kntu.ac.ir - \\ a.sadeghi@kntu.ac.ir - peymanazari1993@gmail.com
}

KEYWORDS: Ubiquitous Computing, Geolocation, RFID, Jewellery Management, GIS.

\begin{abstract}
:
Addressing and geolocation for indoor environments are important fields of research in the recent years. The problem of finding location of objects in indoor spaces is proposed to solve in two ways. The first, is to assign coordinates to objects and second is to divide space into cells and detect the presence or absence of objects in each cell to track them. In this paper the second approach is discussed by using Radio Frequency Identification technology to identify and track high value objects in jewellery retail industry. In Ubiquitous Sensor Networks, the reactivity or proactivity of the environment are important issues. Reactive environments wait for a request to response to it. Instead, in proactive spaces, the environment acts in advance to deal with an expected action. In this research, a geo-sensor network containing RFID readers, tags, and antennas which continuously exchange radio frequency signal streams is proposed to manage and monitor jewellery galleries ubiquitously. The system is also equipped with a GIS representation which provides a more user-friendly system to manage a jewellery gallery.
\end{abstract}

\section{INTRODUCTION}

To achieve a ubiquitous environment, sensor networks are taken more into consideration today. Radio Frequency Identification Technology is an approach which is efficient for object identification and tracking in indoor spaces. Two approaches are usually used for indoor geolocation and addressing include quantitative methods which are based on geometrical coordinates and qualitative techniques which are known as cellular or symbolic spaces. In symbolic spaces RFID technology can be used to identify presence of objects in each cell. In this paper the application of RFID based systems in jewellery retail business is discussed. Many applications in retail, supply chain, manufacturing, transportation, tracking, and positioning are applied for RFID technology. In the context of jewellery management system, (Nasser 2007) presents a natural application of RFID technology for tracking and tracing in jewellery industry. Jewellery items are tagged with tamperevident tags and scanned daily. (Neubert et al. 2010) applied RFIDs for supply chain in jewellery industry. (Neubert et al. 2010) discusses benefits and applications of RFID based inventory systems. (Neubert et al. 2010) discusses the usage of RFID in retailing in general. None of them have discussed accuracy of system. The innovation of this paper is first to present a geo-sensor network model for RFID management system in retail inventory, and second is to propose a GIS to manage jewelleries in a gallery. The rest of this paper is organized as follows: section 2 discusses geolocation definition and techniques. In section 3 RFID technology and applications are presented. Section 4 introduces RFID based jewellery management system. The results are presented in section 5 . Finally, the research is concluded in section 6.

\section{GEOLOCATION AND RFID BASED GEO-SENSOR NETWORKS}

Geolocation is a method to identify or find geographic position of an object. The object can be a human, car, postal package, pet, or even a high value product in retail and supply chain (Beal 2003). Geolocation is almost similar to positioning systems, but in geolocation the purpose is to find a meaningful location. In other words, geolocation does not mean to assess only geographic coordinates. There is several ways to identify geolocation of an object. Global Navigation Satellite Systems (GNSS) and Global System for Mobile communication (GSM) are systems used to location finding, but they aren't available for indoor spaces. Using Wi-Fi antennas is another way to locate objects. By having the position of Wi-Fi antennas embedded in the environment, the position of an object is estimated. There are several technologies that can be used in wireless geolocation (Beal 2003). IP addresses can also be used for indoor positioning. When a device connect to the internet, the location of the device will be available based on IP because devices have their own IP address. In this paper RFID technology is used to identify and track high value objects in retail businesses. RFID based geolocation is a way to determine the location of an object that is labelled with RFID tags. To identify the location of objects the environment is equipped with RFID tags, RFID readers, and antennas. Generally, there are two ways for addressing and geolocation in indoor spaces. The first, is using quantitative properties of the space like coordinates, and the second, is using qualitative properties. In the second approach the space will be divided into cells and the presence or absence of the object in each cell is considered. Thus topological relationships are used to identify objects location instead of geometrical properties of the space. Using RFID technology which is discussed in this research is a kind of symbolic space approaches. In the next section an overview of RFID technology is discussed. 


\section{RADIO FREQUENCY IDENTIFICATION (RFID) TECHNOLOGY}

\subsection{History}

RFID system was first used in World War II. In World War 11, the British military used the RFID system to identify friend aircrafts from the enemies which were returning from European lands into the UK isles (Neubert et al. 2010; Ko 2010). To identify the friend aircrafts, the UK aircraft produces a signal when they are near the UK isles. If the signal is identified, the aircraft is a friendly one (Ko 2010). After world war RFID technology has been used in trade, security, health care, automotive and many other fields (Venkatesh 2014).

\subsection{Automatic Identification and Proactive Environments}

Automatic Identification is a technology to help machines to identify humans and objects. Auto ID is a method to gain information about objects without any help of humans (Wyld 2010). In Ubiquitous Sensor Networks (USN), the environment can be proactive which means it doesn't wait for an action to takes place and then react to it (Irlbacher et al. 2014). In fact, the environment continuously acts in advance to deal with provoking actions. Technologies like barcodes and RFIDs are used in automatically identifying objects in the environment.

\subsection{RFIDs and barcodes}

As mentioned in the previous section, RFID technology and barcodes are both Automatic ID systems. Both of them are used in identification of objects and gathering information about them. The main difference between these two technologies is the way of reading objects. In barcode systems, the device (reader) scans a printed code but in RFID technology, as its name indicates, the reader scans a tag by radio frequency (Wyld 2010).

RFID systems have more advantages than Barcodes. Thus, Barcode technology is replaced with RFID technology in many fields. In the following table the main differences between RFID systems and Barcode technology are summarized.

\begin{tabular}{|l|l|}
\hline RFID tech. & Barcode tech. \\
\hline $\begin{array}{l}\text { Reduces time to identify } \\
\text { objects. }\end{array}$ & $\begin{array}{l}\text { Need more time to } \\
\text { identify objects. }\end{array}$ \\
\hline $\begin{array}{l}\text { Does not require "line } \\
\text { of site" to scan tags. }\end{array}$ & $\begin{array}{l}\text { Need "line-of-site" to } \\
\text { scan tags. }\end{array}$ \\
\hline $\begin{array}{l}\text { Multiple RFID tags can } \\
\text { be read simultaneously } \\
\text { (100 tags per sec). }\end{array}$ & $\begin{array}{l}\text { Barcode readers read } \\
\text { tags one by one. }\end{array}$ \\
\hline $\begin{array}{l}\text { RFID tags are able to } \\
\text { cope with harsh and } \\
\text { dirty environments. }\end{array}$ & $\begin{array}{l}\text { Barcodes cannot be } \\
\text { read if they become } \\
\text { dirty or damaged. }\end{array}$ \\
\hline $\begin{array}{l}\text { RFID tags information } \\
\text { can be updated. }\end{array}$ & $\begin{array}{l}\text { Barcode information } \\
\text { cannot be updated. }\end{array}$ \\
\hline $\begin{array}{l}\text { Identification from } \\
\text { different ranges. }\end{array}$ & $\begin{array}{l}\text { Only close range } \\
\text { identification. }\end{array}$ \\
\hline
\end{tabular}

Table 1. RFID vs. Barcode

\subsection{How RFID systems work}

The RFID systems consist of two main components, a reader and a tag (Li and Becerik-Gerber 2011). There should be a third part that can link the RFID components to larger information systems (Wyld 2010). This technology uses radio waves to identify objects (Sood and Malik). The RFID reader receives the radio waves that emitted from tags within its range. After that, reader sends the information of tags to software platform for further processes (Kim, Jeong, and Park 2013). RFID tags fall into two general categories, active and passive, depending on their source of electrical power (Venkatesh 2014). Active RFID tags contain their own power source, usually on-board battery. Because of having own power source, active tags transmit a stronger signal, and reader can access them from further away. Active RFID systems typically work better on items tracked over long distances. Passive tags obtain power from the signal of an external reader. Passive tags work based on backscattering of the carrier wave emitted by reader and modulating it with a unique signal. This means that the antenna should be able to collect power from the incoming signal and also to transmit the outbound backscatter signal.

\subsection{RFID applications}

Because of the characteristics of RFID technology, it has wide range of applications in retail, tracking objects, supply chain, indoor localization, manufacturing and etc. Tracking and tracing involves the tagging of an item and recording its movement throughout its life through the supply chain. Each movement of the item is an event that occurs at a specific and discrete time and location. Typically, events are recorded by receiving radio signals from an RFID tag that is affixed to an item as it passes through the field of a reader. The data from the signal then is collected and is aggregated by a central system that maintains information about the latest event and the history of all events pertaining to that item (Nasser 2007). One of the RFID applications in retail is using the smart shelves. Smart shelve contain a reader above it. If all of the goods have RFID tags, this system can alert and prevent the out-of-stock situation (Gaukler and Seifert 2007). To determine the price of goods purchased in stores, the use of this system has increased the speed and economy in time. In the context of indoor localization RFIDs can be used to locate and track a targeted object.

\section{JEWELLERY MANAGEMENT SYSTEM}

Jewellery trade has been one of the luxury and high benefit businesses during years. Due to the high average of product cost in this business, management and protection of them in both supply chain and retail applications are important issues (Wyld 2010). Jewelry displays are usually faced with various challenges. Hundreds of jewelleries must be checked every day. Jewelleries must be set up daily and then stored in the safes in the evening. Because they are small in volumes and high in price they have the possibility to be lost or stolen. Jewellers must be aware of not only strangers, but also their staffs. Many jewellery displays avoid to promote their business because of these difficulties and challenges in census and security. Furthermore, jewellers are interested to know about jewelleries which are more attractive to their customers or the ones which are more sold in a specific period of time. Customers are usually interested to test jewelleries and watch them closely, so the staffs must continuously be aware of them. Sensor networks containing RFID technology beside GI systems can be used to solve many of these problems. In the following, some scenarios are presented to specify the benefits of using RFID geo-sensor networks and integrating it with GIS in jewellery management system. 
- Every day in a short time the inventory of the gallery is counted. The management can see where a specific jewellery is (geo-location) in the gallery and find every information about the product such as value, certificate, and image. Again at the end of the day the inventory is counted and find which products are sold, or lost.

- The customer can test jewelleries in front of trays. As soon as the jewellery is placed out of the range of RFID reader the system alarms and lock the doors (fig.1). Because the space is covered with RFID readers the product can be tracked easily.

- The management can see which product is examined by each customer, and which one is more attractive for them.

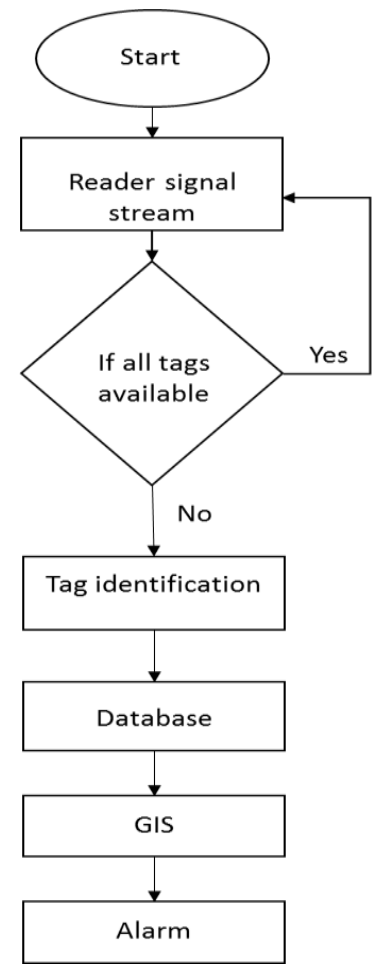

Figure 1. Jewellery security system

\subsection{System Architecture}

For this research the UHF (900 MHZ) RFID reader DOTR-900 of the D.O.TEL Company has been used which Table 2 shows specifications of the device. Passive tags are also used to identify various jewellery products. The system is developed by $\mathrm{C \#}$ programming language and MySQL database management system.

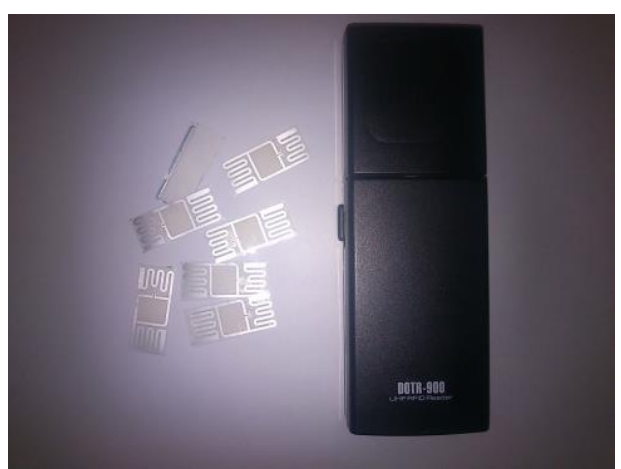

Figure 2. DOTR-900 UHF RFID reader \& tags

\begin{tabular}{|l|c|c|}
\hline \multirow{2}{*}{$\begin{array}{l}\text { Item } \\
\text { specifications }\end{array}$} & \multicolumn{2}{|c|}{ Details } \\
\cline { 2 - 3 } & Frequency range & $860 \sim 970 \mathrm{MHz}$ \\
\cline { 2 - 3 } & Max power & $1^{\mathrm{w}}$ \\
\cline { 2 - 3 } & UHF(900MHz) & $\begin{array}{c}\text { ISO1800-6C, } \\
\text { RFID }\end{array}$ \\
& $\begin{array}{c}\text { EPC Class 1, } \\
\text { Gen2 }\end{array}$ \\
\cline { 2 - 3 } & Antenna gain & TBD \\
\hline Bluetooth & $\begin{array}{c}\text { Serial profile } \\
\text { support }\end{array}$ & $115.200 \mathrm{BPS}$ \\
& & \\
\hline
\end{tabular}

Table 2. DOTR 900 UHF RFID reader specification

The system architecture is shown in fig. 3. As soon as a product is identified by reader the address and attributes of the product are extracted from a database and are represented in a GIS. The addressing system is based on a geolocation approach in which each place for products in jewellery trays comes up with a code (fig. 3.).

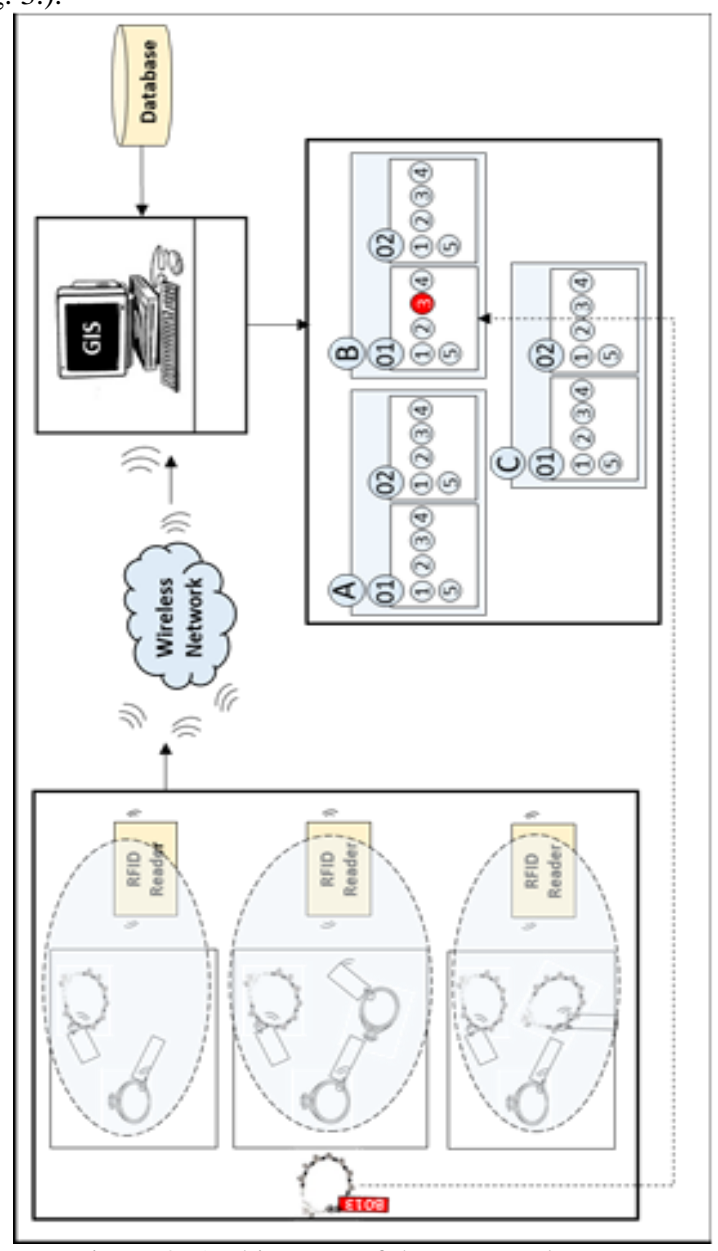

Figure 3. Architecture of the proposed system. 


\section{RESULTS}

To evaluate the proposed system regarding the fact that jewellery retail is an expensive business, accuracy of the system in inventory management is an important issue. Therefor to evaluate the performance of system, 7 plates each one contain 40 jewellery were read 10 times with an RFID reader. The duration of reading for each plate was $5 \mathrm{sec}$. The number of detected tags for each time epoch are presented in table 3. As displayed in the table, just in two cases all tags were read. Thus, with moving RFID reader normally on top of each plate in $5 \mathrm{sec}$ 37 tags were detected in average which is not provide the $100 \%$ accuracy needed for such an expensive business.

\begin{tabular}{|c|c|c|c|c|c|c|}
\hline $\begin{array}{c}\text { Plate } \\
\mathbf{1}\end{array}$ & $\begin{array}{c}\text { Plate } \\
\mathbf{2}\end{array}$ & $\begin{array}{c}\text { Plate } \\
\mathbf{3}\end{array}$ & $\begin{array}{c}\text { Plate } \\
\mathbf{4}\end{array}$ & $\begin{array}{c}\text { Plate } \\
\mathbf{5}\end{array}$ & $\begin{array}{c}\text { Plate } \\
\mathbf{6}\end{array}$ & $\begin{array}{c}\text { Plate } \\
\mathbf{7}\end{array}$ \\
\hline 38 & 38 & 38 & 33 & 38 & 34 & 37 \\
\hline 37 & 33 & 36 & 35 & 36 & 38 & 33 \\
\hline 35 & 36 & 34 & 38 & 36 & 36 & 38 \\
\hline 35 & 39 & 37 & 40 & 38 & 38 & 38 \\
\hline 38 & 36 & 37 & 36 & 39 & 39 & 35 \\
\hline 35 & 37 & 36 & 39 & 38 & 38 & 38 \\
\hline 38 & 39 & 38 & 38 & 38 & 38 & 34 \\
\hline 38 & 39 & 37 & 37 & 37 & 38 & 36 \\
\hline 38 & 37 & 37 & 35 & 35 & 38 & 37 \\
\hline 37 & 35 & 37 & 37 & 37 & 39 & 40 \\
\hline
\end{tabular}

Table 3. Number of detected tags for each plate

Therefor another test were designed to identify the time needed to detect all tags in each plate. The results are presented in table 4. The test was performed 10 times for each plate. These results illustrate that to read all tags in each plate $8.45 \mathrm{sec}$ needed in average. It means for a gallery with about 3000 pieces of jewellery and 75 plates 10-11 minutes needs to read all tags.

\begin{tabular}{|c|c|c|c|c|}
\hline $\begin{array}{c}\text { Plate } \\
\mathbf{1}\end{array}$ & $\begin{array}{c}\text { Plate } \\
\mathbf{2}\end{array}$ & $\begin{array}{c}\text { Plate } \\
\mathbf{3}\end{array}$ & $\begin{array}{c}\text { Plate } \\
\mathbf{4}\end{array}$ & $\begin{array}{c}\text { Plate } \\
\mathbf{5}\end{array}$ \\
\hline 8.13 & 6.03 & 5.25 & 7.24 & 7.82 \\
\hline 11.54 & 14.01 & 7.89 & 4.63 & 7.41 \\
\hline 9.61 & 6.47 & 8.97 & 8.38 & 9.34 \\
\hline 12.13 & 6.61 & 6.61 & 7.51 & 7.56 \\
\hline 11.77 & 7.92 & 5.71 & 6.01 & 7.46 \\
\hline 6.21 & 7.11 & 5 & 11.84 & 5.74 \\
\hline 13.7 & 6.31 & 5.87 & 12.55 & 12.83 \\
\hline 11.65 & 6.61 & 8.91 & 10.6 & 17.24 \\
\hline 7.94 & 6.83 & 7.36 & 7.37 & 6.41 \\
\hline 6.89 & 10.81 & 9.57 & 7.55 & 7.65 \\
\hline
\end{tabular}

Table 4 . The time to read all tags in each plate.

\section{CONCLUSION}

This paper has discussed geolocation which is about finding a meaningful location for objects in the environment instead of using only raw coordinates. In indoor spaces cellular and symbolic space approaches are usually used for addressing and geolocation. In this paper, a symbolic RFID based inventory management system for jewellery industry was proposed. The system also included a GIS representation of tray and jewellery locations. The proposed system would solve a lot of problems related to retail and inventory management and monitoring in the context of jewellery industry. The evaluation of accuracy of the system is a challenging issue, so the future works will focus on ways to evaluate and improve accuracy of the system.

\section{REFERENCES}

Beal, JR, 2003. Contextual Geolocation-A Specialized Application for Improving Indoor Location Awareness in Wireless Local Area Networks, College of Graduate Studies and Research, Minnesota State University-Mankato .

Gaukler, G. M., and R. W. Seifert, 2007. Applications of RFID in supply chains. In Trends in supply chain design and management, Springer 29-48.

Irlbacher, K., A. Kraft, S. Kehrer, and S. A. Brandt, 2014. Mechanisms and neuronal networks involved in reactive and proactive cognitive control of interference in working memory. Neuroscience \& Biobehavioral Reviews.

Kim, S.-C., Y.-S. Jeong, and S.-O. Park, 2013. RFID-based indoor location tracking to ensure the safety of the elderly in smart home environments. Personal and Ubiquitous Computing 17 (8).

Ko, C.-H, 2010. RFID 3D location sensing algorithms. Automation in Construction 19 (5), pp.588-595.

Li, N., and B. Becerik-Gerber, 2011. Performance-based evaluation of RFID-based indoor location sensing solutions for the built environment. Advanced Engineering Informatics 25 (3), 535-546.

Nasser, G. G, 2007. Using RFID for risk mitigation and location assuredness of high-value goods. Paper read at RFID Eurasia, 1st Annual.

Neubert, G., I. Zaoui, C. Dominguez, and B. Ageron, 2010. RFID implementation and supply chain alignment: the case of jewellery in the retail industry. Paper read at 8th International Conference of Modeling and Simulation.

Sood, E. S., and E. M. Malik. Benefits and applications of RFID based inventory system.

Venkatesh, D, 2014. Usage of RFID in retailing- a pervasive technology application. Journal of Radix International Educational and Research Consortium (RIJEB), 3 (1).

Wyld, D. C, 2010. 24-Karat protection: RFID and retail jewelry marketing. International Journal of UbiComp (IJU), 1 (1). 